\title{
Pyrene fate affected by humic acid amendment in soil slurry
} systems

\author{
Yanna Liang*1, Darwin L Sorensen ${ }^{\dagger 2}$, Joan E McLean ${ }^{\dagger 2}$ and Ronald C Sims ${ }^{\dagger 3}$
}

Address: ${ }^{1}$ Department of Civil and Environmental Engineering, Southern Illinois University Carbondale, 1230 Lincoln Dr., Carbondale, Illinois, USA, ${ }^{2}$ Utah Water Research Laboratory, Utah State University, 1600 Canyon Road, Logan, Utah, USA and ${ }^{3}$ Department of Biological \& Irrigation Engineering, Utah State University, 4105 Old Main Hill, Logan, Utah, USA

Email: Yanna Liang* - liang@engr.siu.edu; Darwin L Sorensen - darwin.sorensen@usu.edu; Joan E McLean - jmclean@engineering.usu.edu; Ronald C Sims - rcsims@engineering.usu.edu

* Corresponding author †Equal contributors

Published: 10 September 2008

Journal of Biological Engineering 2008, 2:I I doi:10.1 I86/I754-I6II-2-II

This article is available from: http://www.jbioleng.org/content/2/l/I I

(c) 2008 Liang et al; licensee BioMed Central Ltd.

This is an Open Access article distributed under the terms of the Creative Commons Attribution License (http://creativecommons.org/licenses/by/2.0), which permits unrestricted use, distribution, and reproduction in any medium, provided the original work is properly cited.
Received: 31 October 2007

Accepted: 10 September 2008

\begin{abstract}
Background: Humic acid (HA) has been found to affect the solubility, mineralization, and bound residue formation of polycyclic aromatic hydrocarbons (PAHs). However, most of the studies on the interaction between HA and PAH concentrated on one or two of the three phases. Few studies have provided a simple protocol to demonstrate the overall effects of HA on PAH distribution in soil systems for all three phases.

Methods: In this study, three doses of standard Elliott soil HA (ESHA), 15, 187.5, and I,875 $\mu \mathrm{g}$ $\mathrm{ESHA} / \mathrm{g}$ soil slurry, were amended to soil slurry systems. ${ }^{14} \mathrm{C}$-pyrene was added to the systems along with non-radiolabeled pyrene; ${ }^{14} \mathrm{C}$ and ${ }^{14} \mathrm{CO}_{2}$ were monitored for each system for a period of 120 days.

Results: The highest amendment dose significantly increased the ${ }^{14} \mathrm{C}$ fraction in the aqueous phase within $24 \mathrm{~h}$, but not after that time. Pyrene mineralization was significantly inhibited by the highest dose over the 120-day study. While organic solvent extractable ${ }^{14} \mathrm{C}$ decreased with time in all systems, non-extractable or bound ${ }^{14} \mathrm{C}$ was significantly enhanced with the highest dose of ESHA addition.

Conclusion: Amendment of the highest dose of ESHA to pyrene contaminated soil was observed to have two major functions. The first was to mitigate $\mathrm{CO}_{2}$ production significantly by reducing ${ }^{14} \mathrm{CO}_{2}$ from ${ }^{14} \mathrm{C}$ pyrene mineralization. The second was to significantly increase stable bound ${ }^{14} \mathrm{C}$ formation, which may serve as a remediation end point. Overall, this study demonstrated a practical approach for decontamination of PAH contaminated soil. This approach may be applicable to other organic contaminated environments where active bioremediation is taking place.
\end{abstract}

\section{Background}

Bioremediation has been recognized as an effective approach for polycyclic aromatic hydrocarbon (PAH) contaminated sites. Major characteristics of PAHs are low water solubility and high hydrophobicity, which limits availability to microorganisms. In order to increase the bioavailability of PAHs in soil or sediment, humic substance (HS) addition has been considered to be a better 
choice than chemical surfactant that may cause the loading of soil with chemicals whose future behavior, toxicity, and degradability cannot be predicted [1].

As the most abundant pool of nonliving organic matter in the environment [2] and having a unique constellation of reactive features [3], HS has been studied for its effect on $\mathrm{PAH}$ bioremediation and the possibility of using it as a natural attenuating agent for cost effective, in situ bioremediation [4]. Three major effects have been identified. The first effect is on PAH solubility, with several studies showing increased apparent aqueous solubility [5-12]. The second effect is the enhancement of PAH mineralization and biodegradation [10,13-17]. However, some other studies have shown that HS has no effects on PAH biodegradation [18-24]. The third effect is that HS may bind PAHs and form bound residues. Some characteristics of bound residues are that they are not bioavailable for further degradation, are nontoxic, and can be an environmental bioremediation endpoint [25-28]. The humic acid (HA) fraction of HS has been identified as the primary sink for bound residues of pyrene [29]. Even though pyrene is regarded as a recalcitrant contaminant, its degradation products and metabolites have been isolated and identified in laboratory cultures, soil microcosms, and environmental samples [30-32]. Incorporation of metabolites into soil HA is also considered to be a major mechanism for bound residue formation [26,33].

The distribution of pyrene and its degradation products in soil occurs among three major phases including: (1) air (mineralized as $\mathrm{CO}_{2}$ ), (2) water, and (3) solid. Solid phase pyrene can be separated into two components: (1) organic solvent extractable pyrene, and (2) nonextractable or bound pyrene [29]. While most of the studies on the interaction between HA and PAH evaluated one or two of the three phases, few studies provide a simple protocol to determine the overall effects of HA on PAH distribution in soil systems in all three phases.

A soil sample from the Champion International Superfund Site located in Libby, Montana, was used in this study [34]. This site experienced extensive contamination from wood-treating operations from 1946-1969. In a previous study, Nieman et al. [29] demonstrated that $11 \%$ of the ${ }^{14} \mathrm{C}$ added as radiolabeled pyrene was bound to the native soil organic matter (soil organic carbon of 1.4\%) in biologically active soil microcosms compared to only $3 \%$ in poisoned controls. In the present study, standard Elliott soil humic acid (ESHA) and ${ }^{14} \mathrm{C}$ pyrene mixed with nonradiolabeled pyrene were added to the Libby soil to increase bound residue formation and determine the formation pattern and stability of bound residue formed from newly added contaminants.
The objectives of this study were to: 1) present the distribution and mass balance of pyrene in soil slurry systems amended with ESHA, and 2) determine the short-term stability and degradability of bound residues formed.

\section{Methods \\ Chemicals}

Pyrene (99\%) was purchased from Fluka (Buchs, Switzerland). Radio-labeled $\left[4,5,9,10-{ }^{14} \mathrm{C}\right]$ pyrene (95\% purity, specific activity $=56 \mathrm{mCi} / \mathrm{mmol}$ ) was purchased from Amersham International (Buckinghamshire, England). Analytical reagent grade sodium hydroxide $(\mathrm{NaOH}$ pellets) and potassium hydroxide (KOH pellets) were purchased from Mallinckrodt Baker Inc. (Paris, KY). Methanol and acetonitrile used were high-performance liquid chromatography (HPLC) grade or the equivalent. Ready Gel scintillation cocktail was bought from Beckman Coulter (Fullerton, CA). ESHA was purchased from International Humic Substance Society (IHSS) with a carbon content of $58.1 \%$.

\section{Soil}

The soil material used in this experiment was from the prepared bed land treatment unit 2 (LTU2) at the Champion International Superfund Site in Libby, MT. The soil had been contaminated by a mixture of creosote and pentachlorophenol used as a wood preservative at the site $[34,35]$. The soil sample was passed through a $2.0-\mathrm{mm}$ sieve and homogenized. The homogenized soil was classified as a loam (50\% sand, $38 \%$ silt, $12 \%$ clay) with an organic carbon content of $1.4 \%$. Other physical and chemical properties of the soil sample were: $\mathrm{pH}, 7.6$; potassium, $16 \mathrm{mg} / \mathrm{l} ; \mathrm{NO}_{3}-\mathrm{N},<1.0 \mathrm{mg} / \mathrm{kg} ; \mathrm{NaHCO}_{3}$ extractable phosphorous, $13 \mathrm{mg} / \mathrm{kg}$ (analysis by Utah State University Soil Testing Laboratory). The soil was stored in the dark at $4{ }^{\circ} \mathrm{C}$ until used. The moisture content was $10.2 \%$ (dry weight basis) immediately before use.

\section{ESHA effect on ${ }^{14} \mathrm{C}$ mass balance}

A previous publication has indicated that adding ESHA to soil at doses of 20-200 $\mu \mathrm{g}$ ESHA/g soil consistently increased pyrene mineralization by indigenous microorganisms in soil microcosms, whereas the lowest dose of 10 and other doses from 400 to 3,360 $\mu \mathrm{g}$ ESHA/g soil presented no effect and 10,080 $\mu$ g ESHA/g soil produced inhibition [10]. Based on these dose effects, this study was conducted to evaluate how ESHA amendment affects ${ }^{14} \mathrm{C}$ distribution among air, water, and solids. ESHA at doses of $15,187.5$, and $1,875 \mu \mathrm{g}$ ESHA/g soil slurry was evaluated together with a control that had no ESHA addition. Duplicates of each treatment were analyzed at each sampling time of $1 \mathrm{~h}, 4 \mathrm{~h}, 16 \mathrm{~h}, 24 \mathrm{~h}$, day 7, day 35, and day 120. A total of 56 microcosms were incubated. 
The ESHA $(30,000 \mathrm{mg} / \mathrm{l})$ was dissolved in $0.1 \mathrm{M} \mathrm{NaOH}$ and the $\mathrm{pH}$ was adjusted to 7.0 using $4 \mathrm{M} \mathrm{NaOH}$. Ten gram LTU2 soil (dry weight) in a 125-ml flask was spiked with ${ }^{14} \mathrm{C}$ pyrene mixed with non-radiolabeled pyrene in methanol to make the final pyrene concentration of 100 $\mathrm{mg} / \mathrm{kg}$ and the total disintegrations per minute (DPM) of $312,723 \pm 692$. After the methanol was evaporated in a fume hood, $30 \mathrm{ml}$ of an aqueous solution consisting of either deionized distilled water (DDW) or DDW with different amounts of ESHA were added to each control and treatment, respectively. For the doses of 15, 187.5, and $1,875 \mu \mathrm{g}$ ESHA/g soil slurry, the aqueous solutions contained $0.02 \mathrm{ml}$ ESHA solution with $30 \mathrm{ml} \mathrm{DDW}, 0.25 \mathrm{ml}$ ESHA solution with $29.75 \mathrm{ml}$ DDW, and $2.5 \mathrm{ml}$ ESHA solution with $27.5 \mathrm{ml} \mathrm{DDW}$, respectively. Flasks were then transferred into clean, one-quart mason jars with Teflon coated lids. Carbon dioxide traps consisting of 2.5 $\mathrm{ml}$ of $0.1 \mathrm{M} \mathrm{KOH}$ in $20 \mathrm{ml}$ scintillation vials were also included in each jar. All systems were incubated in the dark at $30^{\circ} \mathrm{C}$ on a rotary shaker at $105 \mathrm{rpm}$.

At each sampling time, ${ }^{14} \mathrm{CO}_{2}$ traps were analyzed by liquid scintillation counting (LSC). The entire volume of the slurry in each flask was transferred to a pre-weighed 50-ml polypropylene centrifuge tube. After centrifuging at 2,000 $\times \mathrm{g}$ for $30 \mathrm{~min}$, the supernatant was transferred into another pre-weighed centrifuge tube. One $\mathrm{ml}$ of supernatant from each treatment and control was pipetted into a 7 -ml scintillation vial with the addition of $6 \mathrm{ml}$ Ready Gel scintillation cocktail and counted for aqueous phase ${ }^{14} \mathrm{C}$. Due to the dark brown color of the aqueous phase of the treatment with 1,875 $\mu \mathrm{g}$ ESHA/g soil slurry, $100 \mu \mathrm{l}$ sample was analyzed as described above to avoid color interference with LSC counting.

The pellet was air-dried in a fume hood for three days. ${ }^{14} \mathrm{C}$ in the solids was extracted by sonication (Tekmar Sonic Disruptor) twice with each extraction lasting $5 \mathrm{~min}$ on a full power, pulsed sonication cycle with $20 \mathrm{ml}$ acetonitrile. The extraction efficiency was calculated as $90 \%$ using standard ${ }^{14} \mathrm{C}$ pyrene. The acetonitrile extract was decanted and centrifuged for $40 \mathrm{~min}$ at 2,000 $\times \mathrm{g}$. The supernatant was transferred to a pre-weighed centrifuge tube and $200 \mu \mathrm{l}$ of each solvent extract (SER) was placed in a $7-\mathrm{ml}$ scintillation vial with $6 \mathrm{ml}$ Ready Gel scintillation cocktail and counted by LSC.

The remaining soil sample was air-dried for three days and then ground in a mortar and pestle. A $0.5 \mathrm{~g}$ subsample was taken for combustion to determine non-extractable or bound residue (BR) ${ }^{14} \mathrm{C}$ (Harvey Biological Oxidizer, RJ Harvey Instrument Corp., $\mathrm{NJ}) .{ }^{14} \mathrm{CO}_{2}$ was trapped in a mixed solution of $50 \%$ ready gel, $40 \%$ methanol, and $10 \%$ monoethanolamine (MEA) and counted by LSC. Instrument recovery analysis was performed every 20 samples using ${ }^{14} \mathrm{C}$ pyrene added to sand as a standard. The average standard recovery was $91 \%$.

\section{Statistical analysis}

JMP IN 5.1 statistical analysis software (SAS institute, NC) was used to analyze all experimental data. Experimental results from mineralized, aqueous, SER, and BR ${ }^{14} \mathrm{C}$ were analyzed using a factorial design with time, treatments, and time * treatments as factors with the Fit Least Squares model. When the factors in the ANOVA and effect tests were determined to be significant ( $\alpha=0.05)$, multiple comparison analyses through LSMeans, Tukey's honest significant difference (HSD) were reported. The HSD was calculated and labeled on each graph, where needed.

\section{Results}

For the three treatments and the control, the overall recovery of ${ }^{14} \mathrm{C}$ added to the soil slurry systems was $100 \pm 4 \%$ for the first $24 \mathrm{~h}$, which indicated that the procedures used for analyzing the dissolved, bound, and extractable phases were valid. Recoveries from day 7 to day 120 ranged between $70 \%$ and $89 \%$. The lower recovery at longer incubation times are likely due to $\mathrm{CO}_{2}$ emissions from the microcosms and/or low trapping efficiency for ${ }^{14} \mathrm{CO}_{2}$ as this was also demonstrated in Nieman's [29] study. However, since the focus of this study was to evaluate the distribution of ${ }^{14} \mathrm{C}$ once it was added to the soil sample, this low recovery would not be expected to effect soil BR formation and measurement.

The ${ }^{14} \mathrm{C}$ in the aqueous phase increased over the first 7 days of incubation with the highest aqueous concentration in the control and $15 \mu \mathrm{g} / \mathrm{g}$ ESHA treatment (Figure 1). After 7 days, the aqueous concentration decreased for all

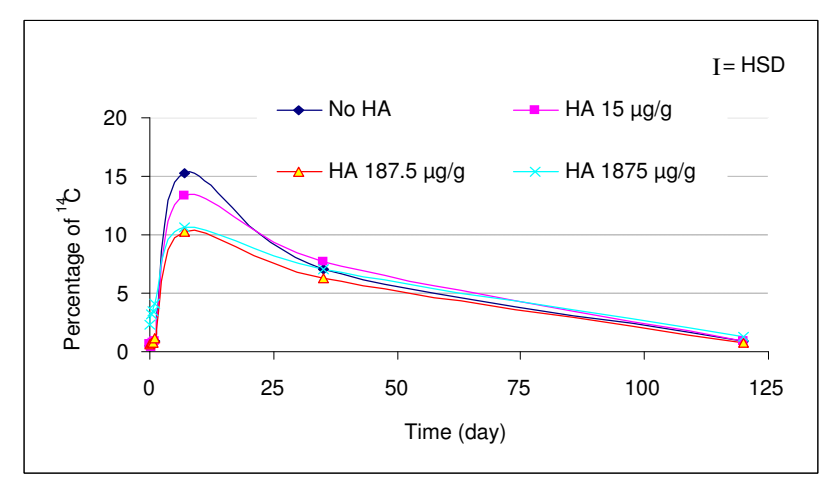

\section{Figure I}

Change in ${ }^{14} \mathrm{C}$ in aqueous phase with time. For the three treatments amended with standard Elliott soil humic acid (ESHA) and the control (no ESHA addition), aqueous phase ${ }^{14} \mathrm{C}$ fraction increased with time to day 7 and then decreased with time. 
systems. During the first $24 \mathrm{~h}$, the highest dose of 1,875 $\mu \mathrm{g}$ ESHA/g soil slurry amendment was associated with a significant increase of ${ }^{14} \mathrm{C}$ in the aqueous phase fraction compared to those of the control and the other two lower doses as shown in Figure 2. Mineralization was observed in the four systems by $24 \mathrm{~h}$ (Figure 3). Initially, the mineralization of pyrene was inhibited with ESHA dosing of 187.5 and $1,875 \mu \mathrm{g} / \mathrm{g}$ compared with the control and lowest ESHA dosing. By day 120, the mineralization at the highest dosing of ESHA was still less than the control.

SER 14C decreased gradually from an average of $85 \%$ measured at $1 \mathrm{~h}$ of incubation to $8-10 \%$ on day 120 for the four systems (Figure 4). This experiment showed that after $14 \mathrm{C}$ pyrene was added to the soil, most of $14 \mathrm{C}$ was associated with the soil matrix and was apparently solvent extractable. When mineralization began at day 1, SER 14C underwent rapid mass transfer from the soil matrix to the aqueous phase and was degraded. A decrease of approximately $40 \%$ of SER 14C was observed between day 1 and day 7 . By the end of the experiment, an average of $9 \%$ of the added 14C remained solvent extractable. Statistical analysis showed that there was no significant difference in SER 14C recovery among the four systems.

BR formation was observed to be a very rapid process (Figure 5). After ${ }^{14} \mathrm{C}$ pyrene was added to the soil, approximately $13 \%$ of the ${ }^{14} \mathrm{C}$ became non-extractable within $1 \mathrm{~h}$. For the control and lowest ESHA dosing, the percentage of ${ }^{14} \mathrm{C}$ BR remained constant at $14 \%$ over the first $16 \mathrm{~h}$ of incubation, then increased by day 7 , and remained constant over the remaining time of the 120 day experiment.

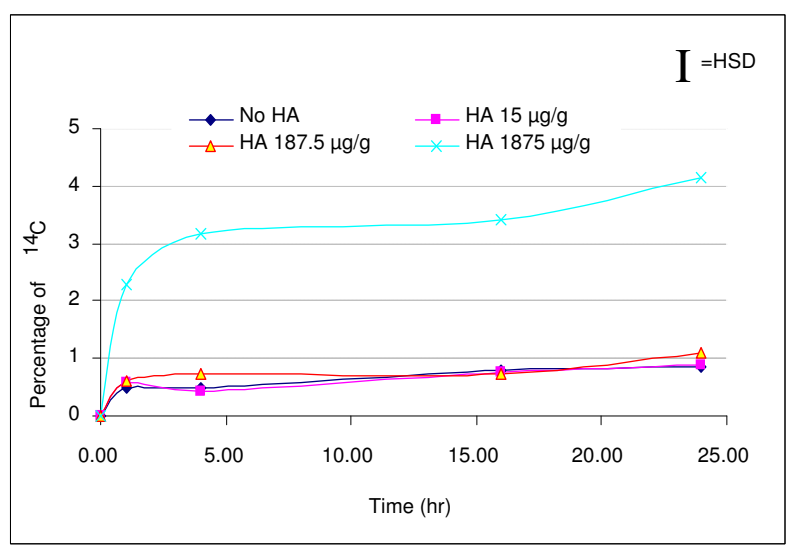

\section{Figure 2}

During the first $24 \mathrm{~h}$, percentages of ${ }^{14} \mathrm{C}$ in aqueous phase change with time. The largest dose of ESHA showed statistically significant enhancement of the aqueous phase ${ }^{14} \mathrm{C}$ fraction compared to the other systems.

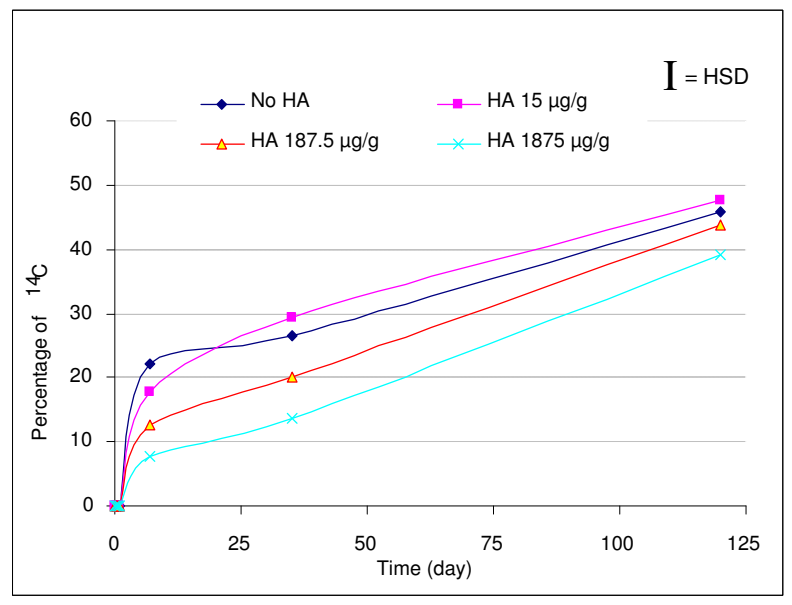

\section{Figure 3}

Cumulative percentages of ${ }^{14} \mathrm{C}$ pyrene as mineralized ${ }^{14} \mathrm{CO}_{2}$ with time. For all four systems, mineralization increased with time within the experimental period. Statistical analysis showed that the two higher doses of ESHA amendment significantly inhibited pyrene mineralization compared to the lowest dose ESHA amendment and the control over time.

For the two higher doses of ESHA amendment, percentages of $\mathrm{BR}{ }^{14} \mathrm{C}$ during the first $16 \mathrm{~h}$ were similar to those of the control and the lowest dose addition with an average of $15 \%{ }^{14} \mathrm{C}$ bound. The highest percentages of $\mathrm{BR}{ }^{14} \mathrm{C}$ were observed by day 1 with $27 \%$ and $38 \%$ of ${ }^{14} \mathrm{C}$ bound for 187.5 and 1,875 $\mu \mathrm{g} \mathrm{ESHA/g} \mathrm{soil} \mathrm{slurry,} \mathrm{respectively.}$

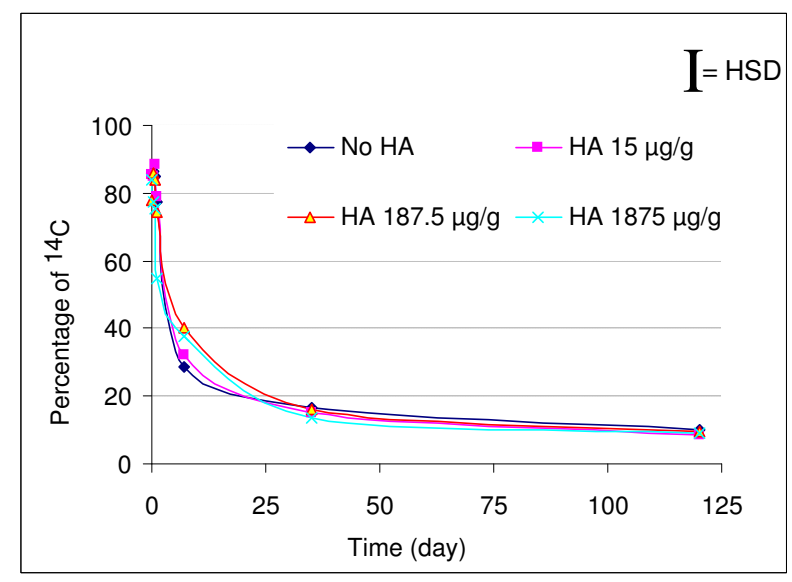

Figure 4

Percentages of ${ }^{14} \mathrm{C}$ as solvent extractable (SER) in the soil matrix change with time. For all four systems, SER fraction decreased with time rapidly during the first 35 days and then slowly to day 120. 


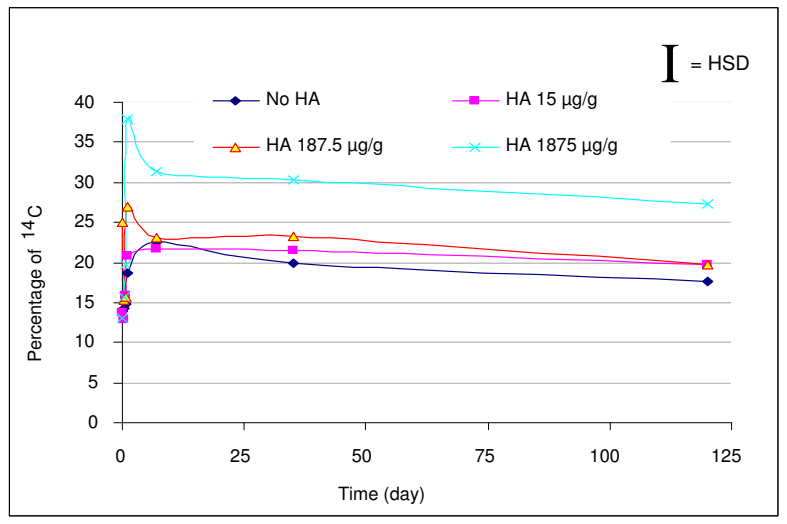

Figure 5

Percentages of ${ }^{14} \mathrm{C}$ as bound residue (BR) change with time. BR fractions in the four systems increased with time during the first $24 \mathrm{~h}$. For the two larger doses of ESHA amendment, I87.5 and I,875 $\mu \mathrm{g} E S H A / g$ soil slurry, BR fractions decreased from day I to day 7 rapidly and then remained constant throughout the experimental period. The highest dose of ESHA addition increased the BR fraction significantly compared to other systems.

The BR decreased by day 7 and remained constant thereafter. Statistical analysis indicated a significant difference between the BR fraction at the highest dose of ESHA amendment and the other three systems.

\section{Discussion}

The SER ${ }^{14} \mathrm{C}$ is the fraction that is associated with the soil matrix by reversible adsorption through a combination of van der Waals forces, hydrogen bonds, hydrophobic interactions, ionic bonds, ligand exchange, and charge transfer complexes [25] and can be extracted by organic solvents $[36,37]$. After ${ }^{14} \mathrm{C}$ pyrene was added to the soil, it was sorbed to the soil matrix with approximately $85 \%$ as SER and $15 \%$ as BR for the four systems. When water and ESHA solution were added to the soil matrix, ${ }^{14} \mathrm{C}$ distribution among air as ${ }^{14} \mathrm{CO}_{2}$, water, and solid phases started to change differently for the different ESHA-dosed systems with time. Biodegradation acted as a driving force to pull SER ${ }^{14} \mathrm{C}$ to the aqueous phase where the compound was mineralized. This is supported by the observation that the aqueous phase ${ }^{14} \mathrm{C}$ fraction increased through day 7 , then decreased to account for only $5 \%$ of the added ${ }^{14} \mathrm{C}$; but mineralization continued to increase for the rest of the time. During the 120-day experimental period, the control without ESHA amendment and the lowest dosing of $15 \mu \mathrm{g}$ ESHA/g soil slurry were always statistically the same regarding ${ }^{14} \mathrm{C}$ distribution among different physical phases of the soil slurry systems.
During the first $24 \mathrm{~h}$, the highest dose of ESHA amendment significantly increased the aqueous phase pyrene fraction by a factor of five compared to those of the other systems. A similar phenomenon was observed in another study with the same ESHA and soil [10]. The role of HA in enhancing organic pollutant solubility has also been reported in two other studies, which indicated that HA could increase apparent solubility of trimethylnaphthalene, methylnaphthalene, and dimethylnaphthalene in aquifer systems [38], and natural organic matter could facilitate transport and enhance desorption of PAHs in aquifer sediments [8]. However, the time-dependent effect of this enhancement has not been discussed before. Moreover, even though the aqueous ${ }^{14} \mathrm{C}$ fraction was increased in this experiment during the first $24 \mathrm{~h}$ with the highest dosing of ESHA, mineralization was not enhanced. This may indicate that the ESHA solubilized radiolabeled material was not bioavailable, possibly through micellar encapsulation, and/or that a community of microbes capable of appreciable mineralization of pyrene in this environment had not yet developed.

During the experimental period, mineralization in the soil slurry system with the highest dose of ESHA amendment was significantly lower compared to the other three systems. Similar conclusions were also drawn from studies by Lesage [9] and Spaccini [39]. These results indicate that a high dose of ESHA may inhibit pyrene mineralization or biodegradation by toxicity or by forming nonbioavailable micelles, which may precipitate or be pushed to the soil matrix by the hydrophobic effect. However, due to different HAs, different soil or sediment or soil slurry systems that have been tested by different researchers, it is difficult to identifya generalized dose for mineralization inhibition for different systems. To our best knowledge, results obtained in one system cannot be simply transferred to other different environments.

In these soil slurry systems, all three doses of ESHA amendment did not show enhancement of pyrene mineralization. In contrast, ESHA was reported to increase the pyrene degradation rate by Mycobacterium sp. JLS [15]. However, that observation was made in a non-slurry static system of ESHA and pyrene without the presence of soil and where the dose of ESHA was not known.

In this study, the BR fraction had four phases of change. First, the BR was formed immediately after pyrene was added to the soil. This spontaneous occurrence of bound residue formation was non-biologically derived as it was also observed in poisoned or sterile samples [25,40-42]. Second, the BR fraction increased with time by $24 \mathrm{~h}$ for the two higher doses of ESHA and by day 7 for the control and the lowest dosing of ESHA. A similar trend was reported when pyrene was added to municipal biowaste 
[43]. These two phases of change can be explained by a hydrophobic sorption mechanism proposed by Karickhoff [44] and Robinson et al. [45], which describes rapid hydrophobic interactions between PAHs and soil hydrophobic surfaces at the first step and a slow migration of PAHs to less accessible sites at the second step.

Third, the BR fraction decreased in the two higher doses of ESHA addition from $24 \mathrm{~h}$ to day 7 when mineralization was active. The decreased $\mathrm{BR}{ }^{14} \mathrm{C}$ fraction did not cause an increase of SER ${ }^{14} \mathrm{C}$, but it correlated well with increased aqueous phase ${ }^{14} \mathrm{C}$ fraction and mineralization, which indicated that ${ }^{14} \mathrm{C}$ released from the $\mathrm{BR}$ fraction was bioavailable and could be mineralized to ${ }^{14} \mathrm{CO}_{2}$ as biodegradation became more aggressive $[26,28,43,46]$. Fourth, after day 7 , the BR fraction in the four systems was constant.

BR formation and PAH retention were significantly increased by adding organic supplements to the soil in other studies [47-49]. However, addition of other supplements including mature compost, bark chips, or forest litter has not shown a positive effect on the BR formation [25]. In this experiment, while the two lower doses of 15 and $187.5 \mu \mathrm{g}$ ESHA/g soil slurry had no significant difference compared to the control during the 120 day period, the largest dose of 1,875 $\mu \mathrm{g}$ ESHA/g soil slurry showed statistically significant enhancement of BR formation. By day 120 , there was $10 \%$ more BR in the highest dose of ESHA amendment compared to that of the control. This is in agreement with the study of ${ }^{13} \mathrm{C}$ labeled 2-decanol, where increased binding through hydrophobic protection by exogenous HA was reported [39].

BR formed during this experimental period was observed to be stable even though biodegradation was active. Therefore, amendment of HA-rich materials to soil slurry systems to increase BR formation could be considered as an effective treatment technology for the Libby Superfund site.

\section{Conclusion}

The protocol developed in this study was effective to evaluate pyrene distribution among different physical phases of soil slurry systems, including air, water, and solid phases. Depending on the dose of EHSA, amending ESHA to soil slurries had significant effects on pyrene apparent solubility, mineralization, and BR formation. These effects can be applied as engineering management alternatives to achieve clean-up goals for PAH-contaminated sites.

\section{Competing interests}

The authors declare that they have no competing interests.

\section{Authors' contributions}

YL carried out the laboratory studies and drafted the manuscript. DLS has been involved in drafting the manuscript and revising it critically for important intellectual content. JEM participated in the statistical analysis and revised the manuscript critically for important intellectual content. RCS has been substantially involved in experimental design, data acquisition, analysis, and interpretation and revising the manuscript critically for important intellectual content. All authors read and approved the final manuscript.

\section{Acknowledgements}

Financial support from the Inland Northwest Research Alliance, the Utah Water Research Laboratory, and the Huntsman Environmental Research Center (HERC) at Utah State University are gratefully acknowledged.

\section{References}

I. Barraclough D, Kearney T, Croxford A: Bound residues: environmental solution or future problem? Environ Pollut 2005, I33(I):85-90.

2. Hedges JI, Oades JM: Comparative organic geochemistries of soils and marine sediments. Org Geochem 1997, 27:319-36I.

3. Fukushima M, Tatsumi K: Functionalities of humic acid for the remedial processes of organic pollutants. Anal Sci 200I, I 7:821-823.

4. Perminova IV, Hatfield K: Remediation chemistry of humic substances: theory and implications for technology. In Use of Humic Substances to Remediate Polluted Environments: from Theory to Practice Edited by: Perminova IV. Netherlands: Springer; 2005:3-36.

5. Conte P, Agretto A, Spaccini R, Piccolo A: Soil remediation: humic acids as natural surfactants in the washings of highly contaminated soils. Environ Pollut 2005, I35(3):515-522.

6. Guetzloff TF, Rice JA: Does humic acid form a micelle? Sci total Environ 1994, I 52:31-35.

7. Herbert BE, Bertsch PM, Novak JM: Pyrene sorption by watersoluble organic carbon. Environ Sci Technol 1993, 27:398-403.

8. Johnson WP, Amy GL: Facilitated transport and enhanced desorption of polycyclic aromatic hydrocarbons by natural organic matter in aquifer sediments. Environ Sci Tech 1995, 29:807-817.

9. Lesage S, Xu H, Novakowski KS, Brown S, Durham L: Use of humic acids to enhance the removal of aromatic hydrocarbons from contaminated aquifers. In Proceedings of the Fifth Annual Symposium on Groundwater and Soil Remediation: October 2-6 1995 Toronto Ontario, Canada; 1995.

10. Liang Y-N, Britt DW, McLean JE, Sorensen DL, Sims RC: Humic acid effect on pyrene degradation: finding of an optimal range for pyrene solubility and mineralization enhancement. Appl Microbiol Biotechnol 2007, 74: I368-1375.

II. Van Stempvoort DR, Lesage S, Novakowski KS, Millar K, Brown S, Lawrence JR: Humic acid enhanced remediation of an emplaced diesel fuel source in groundwater. I. Laboratorybased pilot scale test. J Contam Hydrol 2002, 54:249-276.

12. $\mathrm{Xu} \mathrm{H}$, Lesage $\mathrm{S}$, Durham $\mathrm{L}$ : The use of humic acid to enhance removal of aromatic hydrocarbons from contaminated aquifers. Part I: laboratory studies. Proceedings of the Fourth Annual Symposium on Groundwater and Soil Remediation: Calgary Alberta 1994:635-666.

13. Fava F, Berselli S, Conte P, Piccolo A, Marchetti L: Effects of humic substances and soya lecithin on the aerobic bioremediation of a soil historically contaminated by polycyclic aromatic hydrocarbons (PAHs). Biotechnol Bioeng 2004, 88:2 I4-223.

14. Haderlein A, Legros R, Ramsay B: Enhancing pyrene mineralization in contaminated soil by the addition of humic acids or composted contaminated soil. Appl Microbiol Biotechnol 2001, 56:555-559.

15. Holman H-Y, Nieman K, Sorensen DL, Miller CD, Martin MC, Borch T, McKinney WR, Sims RC: Catalysis of PAH biodegradation by 
humic acid shown in synchrotron infrared studies. Environ Sci Technol 2002, 36: I276-1280.

16. Laor Y, Strom PF, Farmer WJ: Bioavailability of phenanthrene sorbed to mineral-associated humic acid. Water Res 1999, 33:1719-1729.

17. Ortega-Calvo J-J, Saiz-Jimenez C: Effect of humic fractions and clay on biodegradation of phenanthrene by a Pseudomonas fluorescens strain isolated from soil. Appl Environ Microbiol 1998, 64:3123-3126

18. Amador JA, Alexander M: Effect of humic acids on the mineralization of low concentrations of organic compounds. Soil Biol Biochem 1988, 20:185-191.

19. Burgos WD, Pisutpaisal N, Tuntoolavest M, Chorover J, Unz RF: Biodegradation of I-naphthol in the presence of humic acid. Environ Eng Sci 2000, 17:343-35I.

20. Butler JH, Ladd JN: Importance of the molecular weight of humic and fulvic acids in determining their effects on protease activity. Soil Biol Biochem 197I, 3:249-257.

21. Mato MC, Olmedo MG, Mendez J: Inhibition of indoleacetic acid oxidase by soil humic acids fractionated on Sephadex. Soil Biol Biochem 1972, 4:469-473.

22. Pflug $W$, Ziechmann W: Humic acids and the disruption of bacterial cell walls by lysozyme. Soil Bio Biochem 1982, I 4:165-166.

23. Seibel F, Heidenreich S, Frimmel FH: nteraction of Humic Substances and Polycyclic Aromatic Hydrocarbons (PAHs) during the Biodegradation of PAHs. Acta Hydrochim Hydrobiol 1996, 24:1260-266.

24. Shimp R, Pfaender FK: Influence of naturally occurring humic acids on biodegradation of monosubstituted phenols by aquatic bacteria. Appl Environ Microbiol 1985, 49:402-407.

25. Eschenbach A, Mescher H, Wienberg R, Mahro B: Humification of PAH and TNT during bioremediation - evaluation of long term risk and sustainability. In Treatment of Contaminated Soil: Fundamentals, Analysis, Applications Edited by: Stagmann R. Berlin: Springer; 200I:27I-29I.

26. Richnow HH, Eschenbach A, Mahro B, Seifert R, Wehrung P, Albrecht $\mathrm{P}$, Michaelis $\mathrm{W}$ : The use of I3C-labelled polycyclic aromatic hydrocarbons for the analysis of their transformation in soil. Chemosphere 1998, 36:2211-2224.

27. Richnow HH, Eschenbach A, Mahro B, Kastner M, Annweiler E, Seifert $\mathrm{R}$, Michaelis $\mathrm{W}$ : The formation of nonextractable soil residues: a stable isotope approach. Envirn Sci Technol 1999, 33:376I-3767.

28. Eschenbach A, Kastner M, Wienberg R, Mahro B: Microbial PAH degradation in soil material from a contaminated site-mass balance experiments with Pleurotus ostreatus and different 14C-PAH. In Contaminated soil ' 95 Edited by: Van den Brink, et al. Netherlands: Kluver Academic Publication; 1995:377-378.

29. Nieman JKC, Sims RC, Sims JL, Seorensen DL, Mclean JE, Rice JE: [ I4C]Pyrene bound residue evaluation using MIBK fractionation method for creosote-contaminated soil. Environ Sci Technol 1999, 33:776-78I.

30. Liang Y-N, Gardner DR, Miller CD, Dong C, Anderson AJ, Weimer BC, Sims RC: Study of Biochemical Pathways and Enzymes Involved in Pyrene Degradation by Mycobacterium sp. Strain KMS. Appl Environ Microbiol 2006, 72:782I-7828.

31. Liang Y-N: Degradation and intermediates of pyrene by Mycobacterium sp. JLS, KMS, and MCS, isolated from soil at a former wood-preserving facility. In MS thesis Utah State University, Civil and Environmental Department; 2003.

32. Cerniglia CE: Recent advances in the biodegradation of polycyclic aromatic hydrocarbons by Mycobacterium specie. In The utilization of bioremediation to reduce soil contamination: problems and solutions Edited by: Sasek V. Netherlands: Kluwer Academic Publishers; 2003:5I-73.

33. Ressler BP, Kneifel H, Winter J: Bioavailability of polycyclic aromatic hydrocarbons and formation of humic acid-like residues during bacterial PAH degradation. Appl Microbiol Biotechnol 1999, 53:85-91.

34. USEPA: Champion international superfund site, libby, montana: bioremediation field performance evaluation of the prepared bed land treatment system. In EPA-600/R-95//56; United States Environmental Protection Agency, Washington DC; 1996.
35. Piotrowski MR, Doyle JR: Bioremedial progress at the Libby Montana Superfund Site. In Applied Biotechnology for Site Remediation Edited by: Hinchee, et al. Florida: CRC Press; 1993:240-255.

36. Bollag JM, Myers CJ, Minard RD: Biological and chemical interactions of pesticides with soil organic matter. Sci total Environ 1992, I 23-1 24:205-2 |7.

37. Richnow HH, Seifert R, Hefter J, Kastner M, Mahro B, Michaelis W: Metabolites of xenobiotica and mineral oil constituents linked to macromolecular organic matter in polluted environments. Adv Org Geochem 1994, 22:67I-68I.

38. Molson JW, Frind EO, Van Stempvoort DR, Lesage S: Humic acid enhanced remediation of an emplaced diesel source in groundwater. J Contam Hydrol 2002, 54(3-4):277-305

39. Spaccini R, Piccolo A, Conte P, Haberhauer G, Gerzabek MH: Increased soil organic carbon sequestration through hydrophobic protection by humic substances. Naturwissenschaften 1999, 86( I 0):496-499.

40. Hatzinger PB, Alexander M: Effect of aging of chemicals in soil on their biodegradability and extractability. Environ Sci Technol 1995, 29:537-545.

4I. Kelsey JW, Kottler BD, Alexander M: Selective chemical extractants to predict bioavailability of soil-aged organic chemicals. Environ Sci Technol 1997, 31:214-217.

42. Sims RC: Field Scale Bioremediation: Relationship of Parent Compound Disappearance To Humification, Mineralization, Leaching, Volatilization of Transformation Intermediates. Utah State University, Utah Water Research Laboratory: Logan, UT; 1993.

43. Hartlieb N, Ertunc T, Schaeffer A, Klein W: Mineralization, metabolism and formation of non-extractable residues of I4C-labelled organic contaminants during pilot-scale composting of municipal biowaste. Environ Pollu 2003, I 26:83-91.

44. Karickhoff SW: Sorption kinetics of hydrophobic pollutants in natural sediments. In Contaminants and sediments Volume 2. Edited by: Baker RA. Ann Arbor: Ann Arbor Science; 1980:193-205.

45. Robinson KG, Farmer WS, Novak JT: Availability of sorbed toluene in soils for biodegradation by acclimated bacteria. Water Res 1990, 24:345-350.

46. Eschenbach A, Wienberg R, Mahro B: Formation, long-term stability and fate of nonextractable I4C-PAH-residues in contaminated soils. In Remediation of hazardous waste contaminated soils Edited by: Wise, et al. New York: Marcel Dekker, Inc; 2000:429-448.

47. Conte $P$, Zena A, Pilidis G, Piccolo A: Increased retention of polycyclic aromatic hydrocarbons in soils induced by soil treatment with humic substances. Environ Pollut 200I, II 2(I):27-3I.

48. Hupe K, Luth JC, Heerenklage J, Stegmann R: Enhancement of the biological degradation of contaminated soils by compost addition. In The Science of composting Edited by: Bertoldi, et al. London: Blackie Academic and Professional, London; 1996:913-923.

49. Lotter S, Brumm A, Bundt J, Heerenklage J, Paschke A, Steinhart $H$ Stegmann R: Carbon balance of a PAH-contaminated soil during biodegradation as a result of the addition of compost. In Contaminated soils ' 93 Edited by: Arermdt F, et al. Netherlands: Kluwer Academic Publishers; 1993: 1235- 1245.

Publish with Bio Med Central and every scientist can read your work free of charge

"BioMed Central will be the most significant development for disseminating the results of biomedical research in our lifetime. "

Sir Paul Nurse, Cancer Research UK

Your research papers will be:

- available free of charge to the entire biomedical community

- peer reviewed and published immediately upon acceptance

- cited in PubMed and archived on PubMed Central

- yours - you keep the copyright 